\title{
Novel E-Readiness Accession in Higher Education Institutions in Kenya
}

\author{
Mwirigi Kiula $^{1}$, Esther Waiganjo ${ }^{1}$, John Kihoro ${ }^{2}$ \\ ${ }^{1}$ Jomo Kenyatta University of Agriculture and Technology, Nairobi, Kenya \\ ${ }^{2}$ Cooperative University of Kenya, Karen, Kenya
}

\begin{abstract}
E-readiness is an essential element in the advancement of ICT in higher education.It helps us to understand the ability of higher education institutions to tap into the benefits of the digital age. Studies on ereadiness accession have been focused solely on technology. The people, process and technology nexus is integral in harnessing the opportunities of existing and emerging technology solutions. This study reviews the traditional approaches to e-readiness assessment in higher education and proposes a novel e-readiness assessment model for higher education institutions. The people, process and technology nexus and service quality nutshell are used as the basis for the assessment e-readiness accession. A survey of 5 universities has been carried out. Data has been analyzed using descriptive statistics and bivariate correlation. The e-readiness accession on people, process and technology (ERA PPT) nexus is very significantly and positively correlated with the e-readiness accession on service quality $(E R A S Q)$ nutshell with $r=0.811$ ( $p<0.001)$. The ERA PPT has a very significant positive correlation with the observed overall e-readiness accession index for the institutions surveyed with $r=0.971$ ( $p<0.001)$. ERA SQ on the other hand is also very significantly positively correlated with the observed overall e-readiness accession index for the institutions surveyed with $r=0.933(p<0.001)$.
\end{abstract}

Keywords: Digital age, e-readiness accession, e-readiness assessment, higher education institutions

\section{INTRODUCTION}

ICT is an essential ingredient for quality research, training and innovation in higher education. It is noteworthy that a high degree of e-readiness accession contributes significantly towards the realization of a university's academic and administrative goals (Kashorda \& Waema, 2013). There are many economic and other benefits from the use of digital technology (Economic Intelligence Unit, 2010) in the higher education sector. E-leadership skills are in high demand (Lanvin \& Pamela, 2008) to be able to reap the benefits of digital age. The success of the management of education institutions is pegged on effective e-leaders(Valle, 2015). Effective senior leadership of higher education institutions is necessary in order to achieve significant accession in the e-readiness indicators in higher education (Kashorda \& Waema, 2013). Improvement in the levels of e-readiness can be best achieved in consideration of people, process, and technology (Emerson Network Power, 2013), (Husby, 2012), (Williams \& Leask, 2011) and service quality (Rabaa'i, 2010), (Tarvid, 2008). Ereadiness assessment models need to focus not only on technology and related issues but also on people, process and the overarching service quality considerations for the higher education ecosystem.

Although e-readiness has been studied for over a decade, most studies have mainly focused on countries with some researchers developing organization-specific e-readiness assessment models (Tarvid, 2008). Most e-readiness indices are related to particular themes such as e-commerce and egovernment, while other category includes general indices which measure the capacity of ICT, internet diffusion and other access-related issues without any particular focus on specific aspects of information society (Alaaraj \& Ibrahim, 2014). The existing indices are thus limited to the extent of adequate understanding of e-readiness in unique sectors such as higher education. There has been limited accession to higher stages of e-readiness accession in higher education institutions in Kenya for most of the 17 indicators between 2008 and 2013 (Kashorda \& Waema, 2013) based on KENET's CID E-Readiness Assessment Framework. Although leadership research has increased in diversity, subtlety and intricacy, including the fields of education leadership and educational technology, eleadership research in education, by contrast, has barely emerged into public recognition as a research concept within the recognizable surface of scholarly endeavor (Jameson, 2013). A UNESCO Report 
on e-readiness in schools in Asia argues that as ICT adoption and use in the wider socio-economic context of countries becomes more prevalent, it becomes clear that ICT adoption and policies in education are areas that require further study (Wallet \& Melgar, 2014) - underpinning the need for addition studies on e-readiness and related issues in education.

Noteworthy also, a lot of research in the recent past has focused more on leadership in technologymediated virtual organizations while the success of the management of education institutions is pegged on effective e-leaders(Valle, 2015). Most e-readiness assessments have focused technology (infrastructure and information) as exemplified by the CID E-Readiness Assessment Framework (Kashorda \& Waema, 2013), Addom's E-Readiness Assessment of HEIs in Ghana and Machado's EReadiness Assessment Model (Tarvid, 2008). Considerations of the nexus of people, process and technology as well as service quality have been brief and anecdotal with service quality coming in as an improvement in the Tarvid's E-Readiness Model. This research seeks to bring attention to the link of people, process and technology and overarching service quality in the assessment of e-readiness in the higher education ecosystems.

\subsection{Objective}

The objective of this research is to investigate a novel e-readiness assessment model based on the people, process and technology nexus and the service quality nutshell.

\section{TheORETICAL FraMeWORK}

E-readiness, electronic readiness, is a measure of the degree to which a country, nation, economy or sector may be ready, willing or prepared to obtain benefits which arise from ICTs (Dada, 2006). In the context of the higher education sector, e-readiness is a measure of the sectors (and individual higher education institutions) readiness, willingness or preparedness to tap the benefits and opportunities arising from ICTs (Kashorda \& Waema, The E-Readiness Survey on Kenyan Universities 2013 Report, 2013). In the context of the digital age, e-readiness, determines the ability of higher education to utilize digital age resources and capabilities to advance its cause. E-readiness can also be defined as the ability to sort through, interpret, and process digital knowledge (OpenStax College, 2013)

E-readiness studies have tended to focus on the hardware, networks, software and information but limited in depth with respect to people, process and the leadership orchestration necessary to make these work for the success of organizations and socio-economic sectors. Nevertheless, even in the current form, e-readiness is an essential element in the advancement of ICT in higher education to the extent that in helps us to understand the readiness to tap into the benefits of ICT in higher education. ICT helps institutions to make innovations that are much more successful because it dramatically lowers the costs associated with four essential dimensions of innovation: measurement, experimentation, sharing and replication. It does so by digitizing these dimensions into bits of information and therefore making it possible to create, store and transmit them at virtually no-cost (Directorate-General, Taxation and Customs Union, 2014). This would derive great value in the higher education segment whose special mandate is to drive research and innovation.

E-readiness studies have been done on countries, economic blocks, regions or globally for over a decade. The models used differ for different studies and researchers (Tarvid, 2008). A few researchers have developed e-readiness assessment models that can be applied in the higher education environment.

\subsection{CID E-Readiness Assessment Framework}

The Kenya Education Network has used an e-readiness assessment tool originally developed by the Center for International Development at Harvard University (http://www.readinessguide.org) and modified for e-readiness assessment in Kenya and East Africa for the e-readiness surveys of 2006, 2007 and 2013 (Kashorda \& Waema, 2013). The framework contains 17 indicators grouped into five categories.

The categories and respective indicators include network access (information infrastructure, internet availability, internet affordability, network speed and quality), networked campus (network environment, e-campus), networked learning (enhancing education with ICTs, developing the ICT workforce, ICT research and innovation, ICTs in libraries), networked society (people and organizations online, locally relevant content, ICTs in everyday life, ICTs in the workplace) and 
institutional ICT strategy (ICT strategy, ICT financing, ICT human capacity) (Kashorda \& Waema, The E-Readiness Survey on Kenyan Universities 2013 Report, 2013).

Evidently, these indicators confine to the domains of hardware, software and brainware with a trifle attention given to management, governance and leadership issues impacting e-readiness.

\subsection{Addom's E-Readiness Assessment of HEIs}

An e-readiness assessment model for HEIs in Ghana by Benjamin Addom in 2004 (Tarvid, 2008) identified five categories of variables. The categories include, one, human resources with a focus on the existence of ICT support personnel; two, ICT facilities which focuses on computers, networks and media production facilities, three, academic programs reviewing programs inviting students to study and apply ICT as well as research and internship opportunities for students and staff to study and apply ICT; four, outreach policies that advance the cause of a university without walls and finally, faculty posture focusing on the proficiency in ICT as well as progressiveness and innovativeness in the use of ICT for teaching, learning and outreach.

This model has the strength of being a general framework that is applicable to any HEI environment although it is also considered too simplistic for application in detailed e-readiness assessment or advanced institutions.

\subsection{Machado's E-Readiness Assessment Model}

The e-readiness assessment model advanced by Carlos Machado in 2007 (Tarvid, 2008) identified three categories of indicators. These indicators are, one, the ability of HEI stakeholders to execute current policy and develop future strategy, two, the capacity of the learning stakeholders with respect to knowledge, teaching and learning styles, instructional methodology and techno-cultural acceptance and finally, the facilities including infrastructure and network services.

This model identifies the core stakeholders that the model would target for the e-readiness assessment and maps the specific indicators relevant to the respective indicators. The stakeholders identified include the administration (the ability and provision of facilities including motivation, training, performance appraisal and support for access), faculty/lecturers (capacity including its way of thinking, resistance-acceptance, understanding of new methods and skills) and the students/learners (capacity in terms of behavior, resistance-acceptance, understanding of new methods and skills).

The model has the key advantages of, one, being general enough to be applicable to HEIs and, two, having identified key stakeholders and mapped their functions to the categories of variables with respect to e-readiness. It, however, lacks concrete definitions of variables.

\subsection{Tarvid's E-Readiness Assessment Model}

Focused on the twin goals of model re-usability (de-linked from a particular moment in time) and inclusion of categories of variables rarely used Carlos Tarvid in 2008 developed an e-readiness assessment model for HEI (Tarvid, 2008) that attempts to take advantage of the strengths of preexisting models and mitigate their weaknesses.

Tarvid's e-readiness model (Tarvid, 2008) identifies three distinctive variables. Infrastructure focuses on policies and procedures in administering the infrastructure (especially on governance and the application of best practices/international standards) as well as usage and quality specifically on the application of formal guidelines for service management (help desk management), governance and performance management. Information on the other hand focuses on access of information services such as website and electronic journals. Human capacity (skilled workforce) focuses on the level of education, experience measured by the number of years in service and service quality measured by reliability, responsiveness, rapport and tangibles. Service quality is a function of the ICT function of an organization charged with the responsibility to provide support services including hardware and software maintenance, upgrades and installation, data backup and recovery and to provide these services in a time-effective manner (Rabaa'i, 2010).

The service quality has specific importance in e-readiness. Service quality variables of reliability ability to perform promised services dependably and accurately; responsiveness - willingness to help users and to provide prompt service; rapport - ability to convey a rapport of knowledgeable, caring, and courteous support and tangibles - physical facilities, equipment, and appearance of personnel 
(Rabaa'i, 2010) are thus an important inclusion in Tarvid's e-readiness model for HEI e-readiness assessment. The model however does not focus on ICT proficiency of the users (students and staff) on the premise that this is difficult to measure.

\subsection{People, Process and Technology Approach}

The existing e-readiness assessment models have a strong focus on technology infrastructure, information and human skills. The weakness of granting all attention to technology and anecdotal effort on other aspects of technology readiness is well expounded by the observation that "organizations apply technology to solve complex challenges only to find that the technology multiplies the impact and visibility of the problem" - a technology-first tactic that provides only a temporary fix (Williams \& Leask, 2011). Firm specific factors such as technology resources, the management and the commitment of the individuals involved are important for e-readiness accession (Dada, 2006). Dada (2006) gives management and the commitment of the individuals a special impetus and in essence introduces the second dimension of e-readiness; people!

The importance of visualizing the nexus of people and technology is further highlighted by the postulation of the World Summit on the Information Society that "a well-developed information and communication network infrastructure and applications, adapted to regional, national and local conditions, easily-accessible and affordable, and making greater use of broadband and other innovative technologies where possible, can accelerate the social and economic progress of countries, and the well-being of all individuals, communities and peoples" (Alvarez, 2015). Underscoring the importance of enlarging focus wider than merely technology, the Global Information Technology Report 2015 states that " progress will not be about technology alone" and that technology needs to be developed and applied in the context of government policy (including regulation that stimulates highquality, low-cost network access) and, of course, a sustainable approach to wealth creation.

An analysis of the failure of ICTs to improve learning outcomes has posed that education policymakers and technology advocates have tended to focus on the technology itself to the exclusion of the educational reason for it - taking the approach to provide the technology and then to think about how it might be applied (Behar \& Mishra, 2015). This means that, besides technology, the process of delivering quality outputs and outcomes becomes an essential element of consideration in e-readiness accession including the ability to incorporate technology in the pedagogy (Behar \& Mishra, 2015). An IT readiness evaluation criteria for government organizations (Yesser, 2007) reinforces the process readiness as one of the three proposed dimensions for IT readiness evaluation the other two dimensions being architecture readiness and infrastructure readiness. With respect to process readiness the criteria identifies support processes, process automation and data/information flow as the sub-criteria.This brings into focus, process and thus completes the triangle of people, process and technology.

The nexus of people, process and technology is further visualized in the transformation of the health care sector through connected care (information and infrastructure), empowering people (clients and service providers) as well as effective and efficient systems (seamless sharing of data and information, integrated processes) (Wiggins, 2015). Wiggins (2015) reinforces the need for interoperability of data, processes, software systems and networks as well as the transformation of mindsets emphasizing the people, policy and technology nexus.

The building blocks of Enterprise 2.0, an entity that is able to leverage business and IT strategy to increase effectiveness and efficiency of technology initiatives, are the people, processes and technology that make up the organization (Williams \& Leask, 2011), (Husby, 2012). Enterprise 2.0 would, in this case, suitably be considered an e-ready organization able to leverage ICT to advance its vision and societal advancement. Another study posits that operational efficiency requires an approach that optimizes the relationships between people, process and technology (Emerson Network Power, 2013).

Improving the management of business documents, the information within them and their value across an organization requires close examination not just of the technology used to access and distribute information, but of the processes that underpin how it is managed and the way employees create and use the information - hence the approach is to look at the people, processes and technology within an organization - and optimize each element (Ricoh, 2016). Success depends on the process while the right people make an organization profitable (Widjaya, 2014). Without delicate management of people, process and technology, an organization can falter (Leeuwen, 2014). 
Several studies have attempted to develop possible ways of analyzing or measuring the nexus of people, process and technology. The People, Process and Technology Strategy (PPTS) advocates making the people and processes within the organization more efficient and then giving them the tools and technology to make them more effective (Williams \& Leask, 2011). The PPTS Strategy combines people and strategy together then brings in technology.

Emerson Network Power's White Paper on Data Center Efficiency identifies the key aspects to review for people: increased understanding of relationship between systems, greater ability to see the big picture, increased collaboration across the business, greater need for analytical skills, greater need for business skills, greater need for vendor management; process: well-defined processes, automated processes, integrated operating data, decisions based on data (rather than instinct); and technology: higher availability (uptime), efficiency, scalability (ease-to-expand) and timely upgrades (Emerson Network Power, 2013).

A study on collaborative studies identifies the key issues around people as empowerment, timely response of applications, suitable availability of applications, good internal public relations that generates excitement; process as adopting best practices, involving stakeholders, removing unnecessary process steps and simplifying process interactions; and on technology as optimal performance, optimal availability, failover services/business continuity services, friendly and useful applications (Coleman, 2013).

In the realm of people, process and technology there are three critical challenges on the flipside. These challenges are the process challenge - resulting in delays in service delivery; the technology challenge meaning that the technology options of the organization are not congruent with the goals of the organization and people challenges meaning people have outdated skills and new knowledge (Leeuwen, 2014).

\subsection{Service Quality}

E-readiness studies can be reinforced by service quality measured by reliability, responsiveness, rapport and tangibles (Tarvid, 2008). Service quality as a measure of maturity for e-readiness or an indicator for e-readiness accession is an indicator of the ability of the ICT function of an organization, higher education institution in this case, to provide effective and efficient support (Rabaa'i, 2010) to the people, process and technology eco-system of that organization. It has been considered a key element of e-readiness accession (Tarvid, 2008).

Whereas ICT service quality indicators differ, they revolve around reliability (ability to perform promised ICT support service dependably and accurately), responsiveness (willingness to help users and do so promptly), rapport (ability to convey a caring and courteous attitude) and tangibles (the nature of physical facilities, equipment and appearance of personnel) (Tarvid, 2008) (Rabaali, 2010). The tool is applied for this study as advanced by these studies.

\section{Conceptual Framework}

The assessment of e-readiness for the purpose of this research is based on the three components of people, process and technology being the elements central to the success of an e-ready organization ecosystem (Coleman, 2013) (Williams \& Leask, 2011) (Emerson Network Power, 2013).The study derives the indicators and sub-indicators from people: increased understanding of relationship between systems, greater ability to see the big picture, increased collaboration across the business, greater need for analytical skills, greater need for business skills, greater need for vendor management; process: well-defined processes, automated processes, integrated operating data, decisions based on data (rather than instinct); and technology: higher availability (uptime), efficiency, scalability (ease-to-expand) and timely upgrades (Emerson Network Power, 2013); people's as empowerment, timely response of applications, suitable availability of applications, good internal public relations that generates excitement; process's adopting best practices, involving stakeholders, removing unnecessary process steps and simplifying process interactions; and on technology's optimal performance, optimal availability, failover services/business continuity services, friendly and useful applications (Coleman, 2013) and enriched with suitable components derived from other studies.Some of the critical things to consider about people are their involvement, communicated to and trained while technology is defined by hardware, software, systems architecture and information flows (King-Turner, 2016). 
Service quality is measured around reliability (ability to perform promised ICT support service dependably and accurately), responsiveness (willingness to help users and do so promptly), rapport (ability to convey a caring and courteous attitude) and tangibles (the nature of physical facilities, equipment and appearance of personnel) (Tarvid, 2008) (Rabaa'i, 2010).

The eco-system of the study is captured in Figure 1 below as a unit consisting the people, process and technology (PPT) nexus with the service quality (SQ) nutshell of the core support function and the intersection of the Venn diagram representing the most desirable state - the e-ready HEI.

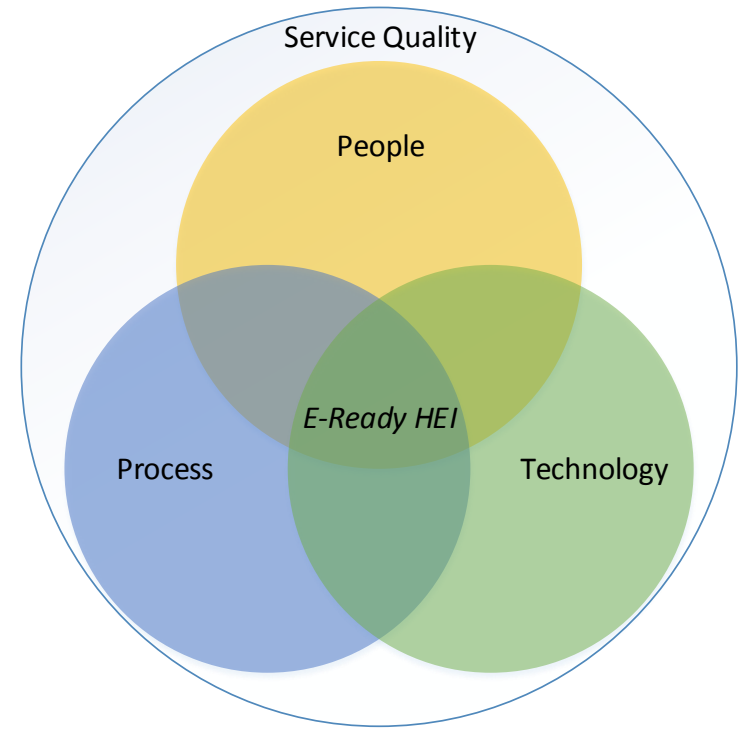

Figure1. HEI E-Readiness Ecosystem (Source: Author)

The PPT nexus and the SQ nutshell is summarized in the conceptual diagram in Figure 2 below.

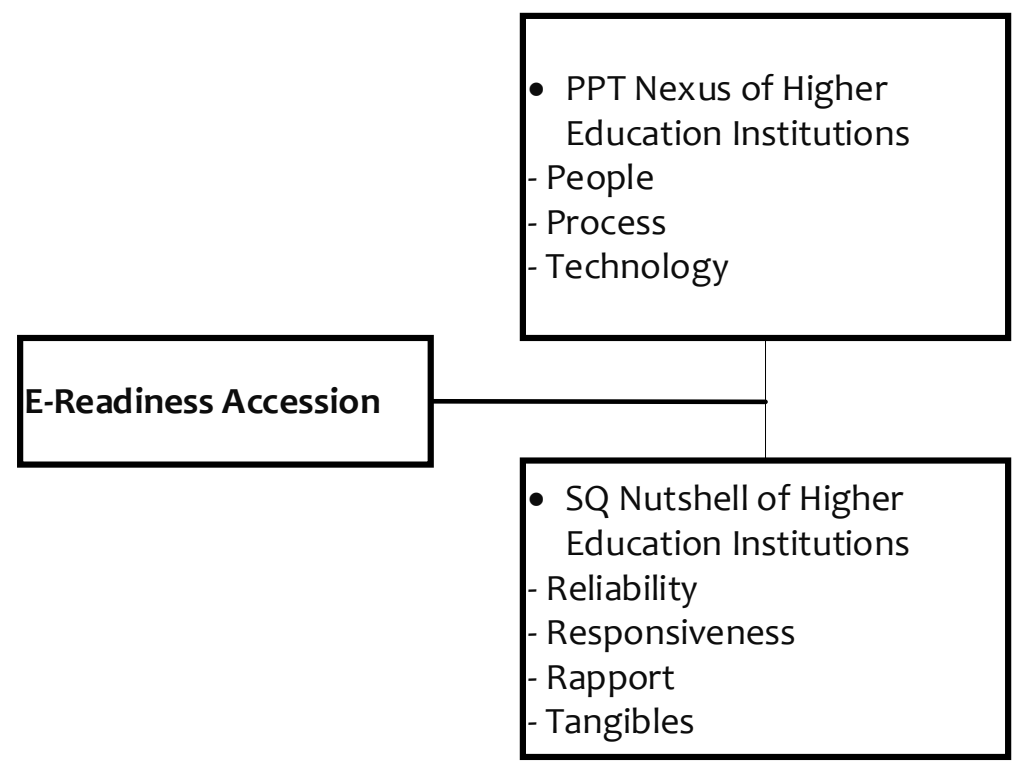

Figure2. E-Readiness Conceptual Framework (Source: Author)

\section{Methodology}

The target population for the study constitutes the 70 institutions of higher education in Kenya as recognized by the Commission for University Education (CUE) as of 2016 (Commission for University Education, 2016). The respondents in this survey will be the students and the staff of the institutions in the sample drawn from the target population.

For the purpose of this study the sampling frame consists of the 40 full-fledged public and private higher education institutions in Kenya (Commission for University Education, 2016) from the following categories of institutions in the higher education eco-system in Kenya: 
Table1. List of Accredited Higher Education Institutions in Kenya

\begin{tabular}{|r|l|l|}
\hline S/No. & \multicolumn{1}{|c|}{ Category } & \multicolumn{1}{|c|}{ Number of Institutions } \\
\hline 1. & Public Chartered Universities & 23 \\
\hline 2. & Public University Constituent Colleges & 10 \\
\hline 3. & Private Chartered Universities & 17 \\
\hline 4. & Private University Constituent Colleges & 5 \\
\hline 5. & Institutions with Letter of Interim Authority & 14 \\
\hline 6. & Registered Private Institutions & 1 \\
\hline & Total & 70 \\
\hline
\end{tabular}

Source: (Commission for University Education, 2016)

The study was based on the 23 public and 17 private chartered universities. This is purposively done on the basis that constituent colleges or institutions under interim authority operate under mentorship of other universities (MOEST, 2014).

Data was collected from the respective institutions with the number of students and staff in each institution and each category being selected through simple random sampling. Simple random sampling was used to mitigate against classification error and minimize the need for advance knowledge of the population (Mukanzi, 2014). Primary data for this research was collected through a closed and open-ended questionnaire hosted online. A ratio of proportional allocation was used to determine the number of respondents per institution to guarantee an equal share of the sample in all the universities sampled (Lehtonen \& Djerf, 2008).

Descriptive statistics was used to obtain the measures of people, process and technology nexus, service quality nutshell and the overall e-readiness.Bivariate correlation was used to analyze the correlation between the perceived e-readiness (general question); the aggregated e-readiness accession index, the people, process and technology nexus and the service quality nutshell. The bivariate Pearson Correlation produces a sample correlation coefficient, $r$, which measures the strength and direction of linear relationships between pairs of continuous variables and, in addition, evaluates whether there is statistical evidence for a linear relationship among the same pairs of variables in the population, represented by a population correlation coefficient, $\rho$ ("rho") (Kent State University Libraries, 2017). For the purpose of congruence, the statistical significance is $p \leq 0.05$. To ensure accuracy SPSS has been selected for data analysis being a well-established data analysis software with inbuilt quality control capability (Sampson, 2012).

General perception questions were utilized to gauge the perceived e-readiness by students and staff in the sampled institutions. Desktop research was utilized to identify the core elements of consideration in the measurement of e-readiness accession in the mold of people, process and technology nexus and the nutshell of service quality.

\section{FINDINGS AND DISCUSSION}

\subsection{General Perception of E-Readiness}

The respondents were presented with a question on their perception of the e-readiness of their respective institutions on a scale of 1-5 (Poor, Fair, Satisfactory, Good, and Excellent). With 82 respondents the results were as shown in Table 2 below.

Table2. Perceived Level of E-Readiness

\begin{tabular}{|l|r|r|r|r|c|}
\hline & $\mathrm{N}$ & Min. & Max. & Mean & Std. Dev. \\
\hline $\begin{array}{l}\text { How do you rate the level of e-readiness of your } \\
\text { institution? }\end{array}$ & 82 & 1 & 5 & 3.15 & 1.134 \\
\hline Valid N & 82 & & & & \\
\hline
\end{tabular}

The results indicates a mean perceived e-readiness of 3.15 with a standard deviation of 1.134 . The perceived e-readiness hover just about 3 on the scale of 1-5, meaning satisfactory.

\subsection{Reliability Test}

The variables, sub-variables and attributes resulting from desktop research on the people, process and technology nexus and the service quality nutshell were as shown in Table 3 below. 
Mwirigi Kiula, et al

Table3. PPT Nexus and $S Q$ Nutshell Variables

\begin{tabular}{|c|c|}
\hline Sub-Variable & Attributes \\
\hline \multicolumn{2}{|c|}{ E-Readiness Accession - People, Process and Technology Nexus } \\
\hline \multirow[t]{10}{*}{ People } & We are excited with automation (new ICT solutions) \\
\hline & We are empowered to serve in our roles \\
\hline & We adapt change easily \\
\hline & Our systems (ERPs, HRMISs, LMISs) give timely response \\
\hline & Our systems (ERPs, HRMISs, LMISs) are up and running when we need \\
\hline & We are involved in decision-making on technology acquisitions \\
\hline & We are well updated \\
\hline & We have technology skills \\
\hline & We have business skills \\
\hline & We have analytical skills \\
\hline \multirow[t]{7}{*}{ Process } & Our processes are well defined \\
\hline & We understand our processes \\
\hline & We easily share data across departments and teams \\
\hline & We have adopted best practices \\
\hline & We continually improve our processes \\
\hline & We make decisions based on data \\
\hline & We monitor the performance of our processes \\
\hline \multirow[t]{7}{*}{ Technology } & Our technology solutions are user-friendly \\
\hline & Our technology solutions are useful for our work \\
\hline & Our systems offer optimal performance \\
\hline & Our systems are optimal uptime \\
\hline & We have business continuity/failsafe mechanisms \\
\hline & We get timely upgrades for hardware and software \\
\hline & We apply best practices/standards in ICT management \\
\hline \multicolumn{2}{|r|}{ E-readiness Accession - Service Quality Nutshell } \\
\hline \multirow[t]{2}{*}{ Responsiveness } & They are willing to help users \\
\hline & They are ready to respond to users requests \\
\hline \multirow[t]{4}{*}{ Reliability } & They provide services as promised \\
\hline & They are dependable in handling user's service problems \\
\hline & They perform services right the first time \\
\hline & They maintain reliable technology and system \\
\hline \multirow[t]{7}{*}{ Rapport } & They make users feel safer in computer transactions \\
\hline & They are consistently courteous \\
\hline & They have the knowledge to answer user's questions \\
\hline & They give users individual attention \\
\hline & They deal with users in a caring fashion \\
\hline & They have the user's interest at heart \\
\hline & They understand the needs of users \\
\hline \multirow[t]{3}{*}{ Tangibles } & They have visually appealing facilities \\
\hline & They appear professional \\
\hline & They provide useful support materials (e.g. documentation, training, videos...) \\
\hline
\end{tabular}

A test of reliability resulted in Cronbach's Alpha Coefficient of $\alpha=.948$ with the control question and $\alpha=.953$ without, for the items used to measure people, process and technology. A similar test was carried out on the elements of service quality resulting in Cronbach's Alpha Coefficient of $\alpha=.913$ with the control question and $\alpha=.936$ without. These results are close to the recommended Cronbach's Alpha of $\alpha=<.70$ meaning that the test items meet the assumptions of the tau-equivalent model, alpha approaches a better estimate of reliability (Tavakol \& Dennick, 2011).

\subsection{People, Process and Technology Nexus and Service Quality Nutshell}

The observed level of e-readiness on the basis of service quality nutshell; the people, process and technology nexus and the combination of the two is shown in Table 4 below.

Table4. Descriptive Statistics of the $S Q$ Nutshell and PPT Nexus

\begin{tabular}{|l|r|r|r|r|r|}
\hline & $\mathrm{N}$ & Min. & Max. & Mean & \multicolumn{1}{c|}{ Std. Dev. } \\
\hline ERA SQ Nutshell & 60 & 2.00 & 5.00 & 3.7533 & .73004 \\
\hline ERA PPT Nexus & 60 & 1.54 & 5.00 & 3.4567 & .73613 \\
\hline E-Readiness Accession Index & 61 & 1.93 & 5.00 & 3.5602 & .70948 \\
\hline
\end{tabular}


Novel E-Readiness Accession in Higher Education Institutions in Kenya

Valid N (listwise)

59

|

The results of bivariate correlation was as follows:

Table5. Correlation of SQ Nutshell, PPT Nexus and Overall E-Readiness Accession

\begin{tabular}{|c|c|c|c|c|}
\hline & & $\begin{array}{l}\text { ERA SQ } \\
\text { Nutshell }\end{array}$ & $\begin{array}{c}\text { ERA PPT } \\
\text { Nexus }\end{array}$ & $\begin{array}{c}\text { E-Readiness } \\
\text { Accession Index }\end{array}$ \\
\hline \multirow[t]{3}{*}{ ERA SQ Nutshell } & Pearson Correlation & 1 & $.811^{* *}$ & $.933^{* * *}$ \\
\hline & Sig. (2-tailed) & & .000 & .000 \\
\hline & $\mathrm{N}$ & 60 & 59 & 60 \\
\hline \multirow[t]{3}{*}{ ERA PPT Nexus } & Pearson Correlation & $.811^{* *}$ & 1 & $.971^{* * *}$ \\
\hline & Sig. (2-tailed) & .000 & & .000 \\
\hline & $\mathrm{N}$ & 59 & 60 & 60 \\
\hline \multirow{3}{*}{$\begin{array}{l}\text { E-Readiness } \\
\text { Accession Index }\end{array}$} & Pearson Correlation & $.933^{* *}$ & $.971^{* * *}$ & 1 \\
\hline & Sig. (2-tailed) & .000 & .000 & \\
\hline & $\mathrm{N}$ & 60 & 60 & 61 \\
\hline
\end{tabular}

The e-readiness accession on people, process and technology (ERA PPT) nexus is very significantly and positively correlated with the e-readiness accession on service quality (ERA SQ) nutshell with $\mathrm{r}=0.811$ ( $\mathrm{p}<0.001)$ with 59 complete observations. The ERA PPT has a very significantpositive correlation with the observed overall e-readiness accession index for the institutions surveyed with $\mathrm{r}=0.971 \quad(\mathrm{p}<0.001)$ with 60 complete observations. ERA SQ on the other hand is also very significantly positively correlated with the observed overall e-readiness accession index for the institutions surveyed with $r=0.933(\mathrm{p}<0.001)$ with 60 complete observations.

\section{Conclusion}

In essence, an accession in the digital age readiness of the people, process and technology has a positive and highly significant influence on the overall state of e-readiness of the institution. Similarly, an improvement in the ICT service quality in the institution has very positive significant influence on the digital age readiness of the institution. The cause-effect relationship between the people, process and technology nexus and the service quality as well as well as the overall aggregated e-readiness and the perceived e-readiness will be an important line to pursue into the future of the research.

\section{ACKNOWLEDGEMENT}

We acknowledge the support of the managements of Jomo Kenyatta University of Agriculture and Technology, St. Paul's University, Daystar University, Meru University of Science and Technology, Kenya Methodist University and the Cooperative University of Kenya for facilitating access to staff and students for data collection. We also appreciate the Kenya Education Network (the national research and education network of the Republic of Kenya) for research support.

\section{REFERENCES}

[1] Alaaraj, H., \& Ibrahim, F. W. (2014). An Overview and Classification of E-Readiness Assessment Models. International Journal of Scientific and Research Publications, Volume 4, Issue 12, 1-5.

[2] Alvarez, L. (2015). Developing the Network for Growth and Equality of Opportunity. In S. Dutta, T. Geiger, \& B. Lanvin, Global Information Technology Report 2015 (pp. 67-72). Geneva: World Economic Forum.

[3] Behar, A., \& Mishra, P. (2015). ICTs in Schools: Why Focusing Policy and Resources on Educators, Not Children, Will Improve Educational Outcomes. In S. Dutta, T. Geiger, \& B. Lanvin, Global Information Technology Report 2015 (pp. 73-78). Geneva: World Economic Forum.

[4] Coleman, D. (2013). Strategies for Successful Enterprise Collaboration: Balancing People, Process and Technology. San Fransisco: Akamai.

[5] Commission for University Education. (2016). Universities Authorized to Operate in Kenya. Nairobi: Commission for University Education. 
[6] Dada, D. (2006). E-Readiness for Developing Countries: Moving the Focus from Environment to Users. The Electronic Journal of Information Systems in Developing Countries 27(6), 1-14.

[7] Directorate-General, Taxation and Customs Union. (2014). Working Paper: Digital Economy Facts \& Figures. Brussels: European Commission.

[8] Economic Intelligence Unit. (2010). Digital Economy Rankings 2010, Beyond e-readiness. New York: Economic Intelligence Unit.

[9] Emerson Network Power. (2013). Integrating People, Process and Technology to Transform Data Center Operations and Performance. Columbus: Liebert Corporation.

[10] Husby, B. C. (2012). Integrating People, Process and Technology in Lean Healthcare. Michigan: University of Michigan.

[11] Jameson, J. (2013). e-Leadership in higher education: The fifth "age" of educational technology research. British Journal of Educational Technology, 889-915.

[12] Kashorda, M., \& Waema, T. (2013). The E-Readiness Survey on Kenyan Universities 2013 Report. Nairobi: Kenya Education Network.

[13] Kent State University Libraries. (2017, May 15). SPSS Tutorials: Pearson Correlation. Retrieved from Kent State University Libraries: http://libguides.library.kent.edu/SPSS/PearsonCorr

[14] King-Turner, M. (2016, January 7). Three Keys to IT System Success: People, Process, Technology. Retrieved from The National B2B Centre: http://www.nb2bc.co.uk/managing_it_projects/articles/?id=181

[15] Lanvin, B., \& Pamela, S. P. (2008). Building E-skills for the Information Age. World Economic Forum.

[16] Leeuwen, D. P. (2014, August 16). People, Process and Technology: The Perfect Combination for Successful Cloud Implementations. Retrieved from ZDNet: http://www.zdnet.com/article/people-process-and-technology-the-perfect-combination-forsuccessful-cloud-implementations/

[17] Lehtonen, R., \& Djerf, K. (2008). Survey Sampling Reference Guidelines: Introduction to Sample Design and Estimation Techniques. Luxembourg: European Communities.

[18] Leonard, L. J., \& Leonard, P. E. (2006). Leadership for Technology Integration: Computing the Reality. The Alberta Journal of Educational Research, 212-224.

[19] MOEST, C. (2014). The Universities Regulations 2014. Nairobi: Government Press.

[20] Mukanzi, C. M. (2014). Effects of Work-Life Balance on Employee Commitment in the Banking Institutions in Kenya. Nairobi: JKUAT.

[21] OpenStax College. (2013). Introduction to Sociology. Rice: Rice University.

[22] Rabaa'i, A. A. (2010). Cultural influences on IS service quality perceptions. Proceedings of 21 st Australasian Conference on Information Systems : Defining and Establishin $g$ a High Impact Discipline. Brisbane: Queensland University of Technology.

[23] Ricoh. (2016, January 7). People, Technology and Processes. Retrieved from RICOH: http://www.ricoh-europe.com/services-solutions/mds/people-technology-and-processes/

[24] Sampson, J. P. (2012). A Guide to Quantitative and Qualitative Dissertation Research. Educational Psychology and Learning Systems Faculty Publications, Paper 1.

[25] Tarvid, A. (2008). Measuring the E-Readiness of HEIs. RIGA.

[26] Valle , I. G. (2015). Emergent leadership: is e-leadership importance in the quality. RIED. Revista Iberoamericana de educación a Distancia, Volume 18, 25-44. 
[27] Wallet, P., \& Melgar, B. V. (2014). Information and Communication Technology (ICT) in Education in Asia: A Comparative Analysis of ICT Integration and E-Readiness in Schools across Asia. Montreal: UNESCO Institute for Statistics.

[28] Widjaya, I. (2014, March 28). Using the 3P's (People, Process, Product) to make Your Business Successful. Retrieved from http://www.smbceo.com/2014/03/28/using-the-3ps-people-processproduct-to-make-your-business-successful/

[29] Wiggins, D. (2015). Connected Healthcare: Extending the Benefits of Growth. In S. Dutta, T. Geiger, \& B. Lanvin, Global Information Technolgy Report 2015 (pp. 87-92). Geneva: World Economic Forum.

[30] Williams, D. E., \& Leask, J. (2011). People, Process, Technology Strategy for Enterprise 2.0. McLean: Booz Allen Hamilton.

[31] Yesser. (2007). IT Readiness Assessment for Government Organizations. The Saudi eGovernment Program (Yesser). 